\title{
The Effect of Sugammadex on Respiratory Functions in Bariatric Surgery
}

\author{
Kocamer Şimşek Betull ${ }^{1 *}$ and Nevhiz Gündoğdu² \\ ${ }^{1}$ Department of Anesthesiology and Reanimation, Sanko University,Turkey \\ ${ }^{2}$ Department of Pulmonology, Sanko University, Turkey
}

Submission: December 13, 2018; Published: January 10, 2019

*Corresponding author: Betül Kocamer Şimșek, Faculty of Medicine, Department of Anesthesiology and Reanimation, Sanko University,Turkey

Abstract

Objective: Bariatric surgeries increased in the last decades likewise obesity. The need for high doses of neuromuscular blocking agents in these surgeries may cause residual paralysis and critical respiratory events and late complications such as hypoxemia, pneumonia, atelectasis, and the possibility of reintubation. The purpose of this study to evaluate the effect of sugammadex on respiratory parameters.

Materials and method: 62 patients are included the study and they were assigned to one of the two groups randomly. LSG operation was performed on all the patients based on standard anesthesia management. In Group S ( $=31$ ), Sugammadex 2mg/kg was administered for the reversal of rocuronium. In Group N ( $\mathrm{n}=31$ ), Neostigmine $0.05 \mathrm{mg} / \mathrm{kg}$ was administered together with atropine $0.02 \mathrm{mg} / \mathrm{kg}$ for the reversal of rocuronium. Extubation duration, Aldrete scores at 5, 10, and 15 minutes after extubation, PACU duration, FEV1 values of RFT, ABG values, mobilization time were analyzed.

Results: In group S, patients have higher PO2 and lower PCO2 levels, shorter mobilization times, and an Aldrete score of 15 sooner, and moreover, they occupy the operating room and PACU to a lesser extent but FEV1 values did not differ between groups.

Conclusion: In conclusion, sugammadex allows a safe and rapid recovery from deep rocuronium-induced neuromuscular blockade after LSG surgery.

Keywords: Sugammadex; Bariatric surgery; Respiratory function tests; Obesity

Abbreviations: ATS: American Thoracic Society; MSD: Merk Sharp and Dohme; LSG: Laparoscopic Sleeve Gastrectomy; PCA: Patient Controlled Analgesia; ABG: Arterial Blood Gas; CPAP: Continuous Positive Airway Pressure; ICU: Intensive Care Unit; RFT: Respiratory Function Tests; PORC: Postoperative Residual Curarization; FRC: Functional Residual Capacity

\section{Introduction}

Having increased in the last decades, the incidence of obesity is associated with numerous health problems $[1,2]$. This leads to an increased need for bariatric surgeries. General anesthesia and paralysis in bariatric surgeries may cause complications including respiratory failure [3,4], need for unplanned or prolonged hospitalization at the intensive care unit, prolonged length of hospital stay and increased mortality. Nevertheless, neuromuscular blockade may be important during laparoscopic surgery in order to optimize ventilation and maintain an adequate pneumoperitoneum [5]. In addition, the need for high doses of neuromuscular blocking agents in these surgeries may cause residual paralysis and critical respiratory events and late complications such as hypoxemia, pneumonia, atelectasis, and the possibility of reintubation [6]. Sugammadex (Bridion (R) Merk Sharp and Dohme (MSD). North Carolina, USA), is a gamma-cyclodextrin, which is a novel agent for the reversal of amino steroidal (rocuronium, vecuronium and to a lesser degree, pancuronium) non-depolarizing neuromuscular blockade $[7,8]$.
Neostigmine is unable to completely reverse a deep neuromuscular blockade and may be associated with muscarinic side effects and thus, it has been proven that sugammadex has more benefits than neostigmine [9-11]. The objective of the present prospective, pilot study is to compare the effects of neostigmine and sugammadex in terms of respiratory function tests, Aldrete scores and Arterial Blood Gas (ABG) values in morbid obese patients undergoing Laparoscopic Sleeve Gastrectomy (LSG) surgery.

\section{Materials and Methods}

The present prospective study was conducted at Hospital of Faculty of Medicine of Sanko University between March and December 2017. The approval of the Institutional Ethics Committee of Sanko University, Gaziantep, Turkey (No: 2017/015 date:25.01.2017) was obtained for the study. Written informed consent was obtained from all the patients.

The study included the patients undergoing LSG. Exclusion criteria were; 
a) being aged $<16$ years or $>40$ years,

b) smoking,

c) ASA grade III or higher,

d) having significant comorbid diseases of the liver, kidneys or heart,

e) having a history of drug or alcohol abuse,

f) having history of lung diseases such as chronic obstructive pulmonary disease and asthma.

LSG operation was performed on all the patients based on standard anesthesia management by using propofol $200 \mathrm{mg}$, rocuronium (Esmeron, Organon. USA) $0.5 \mathrm{mg} / \mathrm{kg}$, fentanyl $0.2 \mathrm{mcg} /$ $\mathrm{kg}$ and sevoflurane and remifentanil infusion $0.25-0.5 \mathrm{mcg} / \mathrm{kg} /$ min IV for maintenance. The patients received dexketoprofen trometamol $50 \mathrm{mg}$ and tramadol $0.5 \mathrm{mg} / \mathrm{kg} 1$ hour before closure and $28 \mathrm{ml}$ ( $8 \mathrm{ml}$ for the liver elevator site and $5 \mathrm{ml}$ for each 4 trocar sites) local anesthetic mixture $(50-50 \%$ bupivacaine $5 \mathrm{mg} / \mathrm{ml}$ and lidocaine \%2) before saturation. All patients received the PatientControlled Analgesia (PCA) containing 400mg tramadol. PCA was set as $0.3 \mathrm{mg} / \mathrm{kg} / \mathrm{hr}$ infusion, locked time as 20 minutes and bolus as $10 \mathrm{ml}$. Monitoring of standard anesthesia included ECG, noninvasive arterial pressure, pulse oximetry, $\mathrm{EtCO}_{2}$ and sevoflurane gas monitoring. The body temperature and skin temperature were controlled and maintained above 35C and below 36.8C respectively. The demographic data including age, gender, and body mass index (BMI), and also remifentanil and rocuronium consumption, anesthesia duration ( $\mathrm{min}$ ), post-anesthesia care unit (PACU) duration (min) were recorded separately.

By using a computer-generated randomization list, 62 patients were included in the study and they were randomly assigned to one of the two groups. In Group S ( $\mathrm{n}=31$ ), Sugammadex 2mg/ $\mathrm{kg}$ was administered for the reversal of rocuronium. In Group N $(\mathrm{n}=31)$, Neostigmine $0.05 \mathrm{mg} / \mathrm{kg}$ was administered together with atropine $0.02 \mathrm{mg} / \mathrm{kg}$ for the reversal of rocuronium. The dosage of all the drugs was calculated based on the lean body weight [12].

After extubation, the patients were transferred to PACU for observation for 30 minutes, or longer if appropriate. In case that a patient required rescue analgesia, pethidine of $20 \mathrm{mg}$ was administered intravenously, and the dose was repeated if necessary. The patients were then transferred to the Intensive Care Unit (ICU) for 24 hours or more, if necessary. Aldrete scores at 5, 10, and 15 minutes after extubation were recorded in PACU. Respiratory Function Tests (RFTs) were conducted on the day before surgery and forced expiratory volume in 1 second (FEV1) values were postoperatively assessed at ICU on the first 2 hours and at the $6^{\text {th }}$ and $12^{\text {th }}$ hours for the study. RFT was repeated, FEV1 values were recorded for the study, and arterial blood gas analysis was done at the same time. For all patients, RFT measurements and evaluations were conducted by a pulmonologist. RFT measurements were obtained by using a Spiropalm 6MWT portable spirometry device. Spirometry was completed in accordance with the guidelines of American Thoracic Society (ATS) [12]. All the tests followed a standardized procedure, with the patients sitting upright, and involved the use of a nose clip with a minimum forced exhalation time of 6 seconds after maximum inhalation. The best values of each FEV1 were used for analysis. The FEV1 values were expressed in liters. The same surgical method was applied to all the patients by the same surgical team.

\section{Statistical analysis}

SPSS 23.0 (IBM Corporation, Armonk New York, USA) and PAST3 (Hammer. Ø. Harper. D.A.T. Ryan. P. D. 2001. Paleontological statistics) programs were used for the analysis of data. Conformity to normal distribution was evaluated by Kolmogorov-Smirnov and Lilliefors correction test for univariate data, and Mardia's test (Dornieden and Hansen Omnibus) for multivariate data. The Levene's test was evaluated for homogeneity of variance. Independent-samples t-test and Bootstrap results were used for the comparison of two independent groups and Mann-Whitney $\mathrm{U}$ test was used together with Monte Carlo simulation technique. Friedman's Two-Way test was applied to examine the repeated measurements of dependent variables and Post Hoc analysis (nonparametric post hoc tests (Miller (1966)) was performed by the Monte Carlo simulation results. Categorical data were compared with each other in the Fisher's Exact test (Exact). Quantitative data were expressed as mean \pm Standard Deviation (SD), median \pm IQR (interquartile range) and the median range (maximumminimum) values in the tables. Categorical data were expressed as number (n) and percentage (\%). The data were examined at confidence level of $95 \%$ and the value of $\mathrm{p}<0.05$ was accepted as statistically significant.

\section{Results}

Table 1: Demographic data.

\begin{tabular}{|c|c|c|c|}
\hline & Group N (n=31) & Group S (n=31) & P Value \\
\hline Age & $30.55 \pm 8.22$ & $28.83 \pm 6.53$ & $>0.05$ \\
\hline BMI & $45.86 \pm 3.49$ & $44.35 \pm 3.18$ & $>0.05$ \\
\hline Gender & $\mathrm{n}(\%)$ & $\mathrm{n}(\%)$ & \\
\hline Female & $15(68.2)$ & $18(78.3)$ & $>0.05$ \\
\hline Male & $7(31.8)$ & $5(21.7)$ & \\
\hline
\end{tabular}

Table 2: Drug consumption, Anesthesia, Extubation, PACU duration and Mobilization hours.

\begin{tabular}{|c|c|c|c|}
\hline & Group N (n=31) & Group S (n=31) & P Value \\
\hline $\begin{array}{c}\text { Rocuronium Con- } \\
\text { sumption (mg) }\end{array}$ & $75.5 \pm 1.7$ & $76.6 \pm 1.3$ & $>0.05$ \\
\hline $\begin{array}{c}\text { Remifentanil Con- } \\
\text { sumption (mcg) }\end{array}$ & $390 \pm 20$ & $400 \pm 20$ & $>0.05$ \\
\hline $\begin{array}{c}\text { Extubation Dura- } \\
\text { tion (min) }\end{array}$ & $28 \pm 18$ & $14 \pm 15^{*}$ & $<0.001$ \\
\hline $\begin{array}{c}\text { Anesthesia Dura- } \\
\text { tion (min) }\end{array}$ & $93 \pm 19$ & $95 \pm 17$ & $>0.05$ \\
\hline $\begin{array}{c}\text { PACU Duration } \\
\text { (min) }\end{array}$ & $35 \pm 6$ & $26 \pm 7^{*}$ & 0.003 \\
\hline $\begin{array}{c}\text { Mobilization Time } \\
\text { (hours) }\end{array}$ & $8(10-9)$ & $6(8-5)^{*}$ & $<0.001$ \\
\hline
\end{tabular}


Table 3: $\mathrm{PO}_{2}$ and $\mathrm{PCO}_{2}$ levels in arterial blood gas analysis ${ }^{*} \mathrm{P}<0.005$.

\begin{tabular}{|c|c|c|}
\hline \multirow{2}{*}{ PCO $_{2}$} & Group N & Group S \\
\hline & $(\mathrm{n}=31)$ & $(\mathrm{n}=31)$ \\
\cline { 2 - 3 } & Median $($ Max-Min $)$ & Median $($ Max-Min) \\
\hline Before Surgery & $36.2(37.1-34.8)$ & $36.1(37.4-35.7)$ \\
\hline In PACU & $44.2(47.8-38.4) *$ & $42.1(45.6-37.2)$ \\
\hline $\mathbf{6}^{\text {th }}$ hour after Surgery & $41.7(52.8-3764) *$ & $40.1(43.7-37.5)$ \\
\hline $\mathbf{1 2}^{\text {th }}$ hour after Surgery & $38.2(44.3-36.4)$ & $38(41.1-36.5)$ \\
\hline PO $_{2}$ & Median $($ Max-Min) & Median (Max-Min) \\
\hline Before Surgery & $106.2(21.1-14.3)$ & $105.9(27.1-15.7)$ \\
\hline In PACU & $88.3(16.8-11.4)$ & $92.5(18.9-10.7)$ \\
\hline $\mathbf{6}^{\text {th }}$ hour after Surgery & $97.7(20.6-12.5)$ & $10.1(22.8-17.4) *$ \\
\hline $\mathbf{1 2}^{\text {th }}$ hour after Surgery & $102.8(23.3-16.5)$ & $104(24.1-18.2)$ \\
\hline
\end{tabular}

The demographic data of the patients including age, gender, and BMI were not different between the groups (Table 1). Table 2 shows anesthetic rocuronium and remifentanil drug dosages, anesthesia duration, extubation duration, PACU duration, and mobilization time. No difference was observed for the drug dosage or duration of anesthesia. However, extubation duration, PACU duration, and mobilization time were significantly shorter in group S. Arterial blood gas values of $\mathrm{PCO}_{2}$ and $\mathrm{PO}_{2}$ did not differ between the groups before the surgery. On the other hand, at the 6th postoperative hour, $\mathrm{PCO}_{2}$ values were lower and $\mathrm{PO}_{2}$ values were higher in group $\mathrm{S}$ and this was statistically significant (Table $3)$. However, at the $12^{\text {th }}$ postoperative hour, $\mathrm{PO}_{2}$ and $\mathrm{PCO}_{2}$ values did not differ between the groups.

Table 4: Aldrete Scores ${ }^{*} P<0.005$.

\begin{tabular}{|c|c|c|}
\hline \multirow{2}{*}{ Aldrete Scores } & Group N & Group S \\
\cline { 2 - 3 } & $\mathbf{( n = 3 1 )}$ & $\mathbf{( n = 3 1 )}$ \\
\cline { 2 - 3 } & Median (Max-Min) & Median (Max-Min) \\
\hline $5^{\text {th }}$ minute & $4(5-3)$ & $6(7-5)^{*}$ \\
\hline $10^{\text {th }}$ minute & $6(7-5)$ & $8(10-7)^{*}$ \\
\hline $15^{\text {th }}$ minute & $8(10-6)$ & $10(10-9)^{*}$ \\
\hline $\begin{array}{c}\text { Variation of Aldrete } \\
\text { Scores }\end{array}$ & & \\
\hline $05-0 c t$ & $-2(-1--3)$ & $-2(-1--4)$ \\
\hline May-15 & $-4(-2--5)$ & $-4(-3--5)$ \\
\hline Oct-15 $^{2}$ & $-2(-1--3)$ & $-2(0--3)$ \\
\hline P value & & $<0.001$ \\
\hline $5 \rightarrow 10$ & $<0.001$ & 0.002 \\
\hline $5 \rightarrow 15$ & 0.003 & $<0.001$ \\
\hline $10 \rightarrow 15$ & $<0.001$ & 0.004 \\
\hline
\end{tabular}

When the Aldrete scores were measured at the $5^{\text {th }}, 10^{\text {th }}$, and $15^{\text {th }}$ minutes after extubation, all the scores were higher in group $\mathrm{S}$ and they were statistically significant (Table 4). Respiratory function tests were performed on the day before surgery, FEV1 values were analyzed, and they were not different between the groups. At 6th postoperative hour at ICU, FEV1 values were lower in group $\mathrm{S}$ but this was not statistically significant. At $12^{\text {th }}$ hour,
FEV1 values did not differ between the groups (Table 5). During the PACU or ICU period, no critical respiratory events were observed. In the present study, none of the patients required reintubation or Continuous Positive Airway Pressure (CPAP) mask ventilation.

Table 5: FEV1 scores.

\begin{tabular}{|c|c|c|}
\hline \multirow{2}{*}{ FEV1 (It/sec) } & Group N & Group S \\
\cline { 2 - 3 } & (n=31) & (n=31) \\
\cline { 2 - 3 } & Median (Max-Min) & Median (Max-Min) \\
\hline FEV1 before surgery (0) & $89(94-72)$ & $88(96-78)$ \\
\hline $\begin{array}{c}\text { FEV1 at } 6^{\text {th }} \text { postoperative } \\
\text { hour (6) }\end{array}$ & $90(100-74)$ & $88(98-82)$ \\
\hline $\begin{array}{c}\text { FEV1 at } 12^{\text {th }} \text { postopera- } \\
\text { tive hour (12) }\end{array}$ & $89(94-71)$ & $88(95-80)$ \\
\hline
\end{tabular}

\section{Discussion}

A morbid obese patient is especially open to critical respiratory events in the postoperative period, including airway obstruction, hypoventilation, hypercapnia, hypoxia and acute respiratory failure [13]. The presence of Postoperative Residual Curarization (PORC) is one of the factors that can provoke the critical respiratory events $[14,15]$. PORC may potentially induce adverse respiratory events and its frequency is often underrated: $30-60 \%$ of all the patients receiving a neuromuscular blocking agent show signs of increased risk of pulmonary complications due to ineffective swallowing and coughing and inaccurate protective reflexes from the larynx and pharynx, as a result of aspiration of secretions [16]. Unfortunately, the functions of the larynx and pharynx muscles are among the last to be restored after muscle relaxation during general anesthesia [13]. However, correct dosing of nondepolarizing neuromuscular blocking agents should be calculated based on ideal body weight in order to avoid the prolonged duration of action and Postoperative Residual Curarization (PORC). Anesthesiologists should initiate a reliable and full recovery from neuromuscular blockade after surgery [13].

PORC could be avoided if neuromuscular function is measured routinely during anesthesia; however, it is not frequently applied as a standard monitorization in daily clinical practices.

In the present study, the effectiveness of sugammadex in the reversal of deep muscle relaxation was not measured as shown in previous studies $[17,18]$ since all the patients required a TOF count of at least 2 twitches before the reversal. The anesthesiologic approach is based on choosing the anesthetic drugs that have least potential for accumulation in bariatric surgery. This allows a more rapid and reasonable recovery and contributes to the reduced duration of perioperative time $[19,20]$. Complete recovery from neuromuscular blockade is crucial for fast-tracks discharge. Even small degrees of Postoperative Residual Curarization (PORC) increase the incidence of critical respiratory events in PACU [21], which is associated with delayed discharge time from PACU [22]. Sugammadex has been shown to provide an effective and complete reversal of muscle relaxant agents [23]; therefore, it can be asserted that shorter extubation duration, higher $\mathrm{PO}_{2}$ and lower $\mathrm{PCO}_{2}$ levels in the PACU and shorter mobilization times in 
the patients, who receive sugammadex, may be associated with a more effective reversal effect. Also, the patients, who received sugammadex, reached an Aldrete score of 15 sooner. All these results caused occupying the operating room and PACU lesser.

In bariatric anesthesia administration. muscle tone is lost on induction. Thus, a reduction in lung volume and Functional Residual Capacity (FRC) may occur. FEV1 values and ABG values were measured in the present study to evaluate respiratory functions. Spirometry is a very useful, non-invasive, globally accepted method. It is known that during the early period after obesity surgery, there is a significant reduction in spirometric values [24]. However, in the present study, no difference at FEV1 values between groups was found. This was associated with the age of the population of the present study. Mean age of the current study is under the patient population of other studies. When concerning the other spirometric variables, there is often a decrease in the pulmonary functions after the surgical procedures, since there are numerous factors that affect the performance of the maneuvers such as pain and fear to take a deep breath. In the present study, care was taken in orientation and during the use of analgesia in the procedure to minimize the interference of pain in the measurements.

\section{Conclusion}

In conclusion, sugammadex allows a safe and rapid recovery from deep rocuronium-induced neuromuscular blockade after surgery. Thus, patients have higher PO2 and lower PCO2 levels, shorter mobilization times, and an Aldrete score of 15 sooner, and moreover, they occupy the operating room and PACU to a lesser extent. We conclude that sugammadex can prevent possible respiratory complications better than neostigmine.

\section{Limitations}

FEV1 levels were not studied in early postoperative period, because several patients were referred to spirometry. These FEV1 levels could not be analyzed.

\section{References}

1. Flegal KM, Carroll MD, Kit BK, Ogden CL (2012) Prevalence of obesity and trends in the distribution of body mass index among US adults. 1999-2010. JAMA 307(5): 491-497.

2. Berrington de Gonzalez A, Hartge P, Cerhan JR, Flint AJ, Hannan L, et al. (2010) Body-mass index and mortality among 1.46 million white adults. N Engl J Med 363: 2211-2219.

3. Shenkman Z, Shir Y, Brodsky JB (1993) Perioperative management of the obese patient. Br J Anaesth 70: 349-359.

4. Adams JP, Murphy PG (2000) Obesity in anaesthesia and intensive care. Br J Anaesth 85(1): 91-108.

5. Baltieri L, Santos LA, Rasera I, Montebelo MI, Pazzianotto Forti EM (2014) Use of positive pressure in the bariatric surgery and effects on pulmonary function and prevalence of atelectasis: randomized and blinded clinical trial. Arq Bras Cir Dig 27 Suppl 1: 26-30.

6. Sauer M, Stahn A, Soltesz S, Noeldge Schomburg G, Mencke T (2011) The influence of residual neuromuscular block on the incidence of critical respiratory events. A randomized prospective placebocontrolled trial. Eur J Anaesthesiol 28(12): 842-848.

7. Gaszynski T, Szewczyk T, Gaszynski W (2012) Randomized comparison of sugammadex and neostigmine for reversal of rocuroniuminduced muscle relaxation in morbidly obese undergoing general anaesthesia. Br J Anaesth 108(2): 236-239.

8. Jones RK, Caldwell JE, Brull SJ, Soto RG (2008) Reversal of profound rocuronium-induced blockade with sugammadex: a randomized comparison with neostigmine. Anesthesiology 109(5): 816-824.

9. Blobner M, Eriksson LI, Scholz J, Motsch J, Della Rocca G, et al. (2010) Reversal of rocuronium-induced neuromuscular blockade with sugammadex compared with neostigmine during sevoflurane anaesthesia: results of a randomized controlled trial. Eur J Anaesthesiol 27(10): 874-881.

10. Khuenl Brady KS, Wattwil M, Vanacker BF, Lora Tamayo JI, Rietbergen $H$ (2010) Sugammadex provides faster reversal of vecuronium-induced neuromuscular blockade compared with neostigmine: a multicenter randomized controlled trial. Anesth Analg 110(1): 64-73.

11. Lemmens HJ, El Orbany MI, Berry J, Morte JB, Martin G (2010) Reversal of profound vecuronium-induced neuromuscular block under sevoflurane anesthesia: sugammadex versus neostigmine. BMC Anesthesiol 10: 15 .

12. Miller MR, Hankinson J, Brusasco V, Burgos F, Casaburi R, et al. (2005) ATS American Thoracic Society. Standardization of spirometry. Eur Respir J 26: 319-338.

13. Gaszynski T, Szewczyk T, Gaszynski W (2012) Randomized comparison of sugammadex and neostigmine for reversal of rocuronium-induced muscle relaxation in morbidly obese undergoing general anaesthesia. British Journal of Anaesthesia 108(2): 236-239.

14. Errando CL, Garutti I, Mazzinari G, Díaz Cambronero Ó, Bebawy JF, Grupo Español De Estudio Del Bloqueo Neuromuscular (2016) Residual neuromuscular blockade in the post anesthesia care unit: observational cross-sectional study of a multicenter cohort. Minerva Anestesiol 82(12): 1267-1277.

15. Sundman E, Witt H, Olsson R, Ekberg O, Kuylenstierna R, et al (2000) The incidence and mechanisms of pharyngeal and upper esophageal dysfunction in partially paralyzed humans. Pharyngeal video radiography and simultaneous manometry after atracurium. Anesthesiology 92(4): 977-984.

16. Murphy GS, Szokol JW, Marymont JH, Greenberg SB, Avram MJ (2008) Residual neuromuscular blockade and critical respiratory events in the post anesthesia care unit. Anesth Analg 107(1): 130-137.

17. Fisher DM (1999) Clinical pharmacology of neuromuscular blocking agents. Am J Health Syst Pharm 56(11 Suppl 1): S4-S9.

18. Kopman AF, Eikermann M (2008) Antagonism of non-depolarizing neuromuscular block: current practice. Anaesthesia 64(Suppl 1): 2230.

19. Raeder J (2007) Bariatric procedures as day/short stay surgery: is it possible and reasonable? Curr Opin Anaesthesiol 20(6): 508-512.

20. Servin F (2006) Ambulatory anesthesia for the obese patient. Curr Opin Anaesthesiol 19(6): 597-599.

21. Murphy GS, Szokol JW, Marymont JH, Greenberg SB, Avram MJ, et al. (2008) Residual neuromuscular blockade and critical respiratory events in the postanesthesia care unit. Anesth Analg 107(1): 130-137.

22. Butterly A, Bittner EA, George E, Sandberg WS, Eikermann M, et al. (2010) Postoperative residual curarization from intermediate-acting neuromuscular blocking agents delays recovery room discharge. $\mathrm{Br} \mathrm{J}$ Anaesth 105(3): 304-309. 
23. Abrishami A, Ho J, Wong J, Yin L, Chung F (2009) Sugammadex, a selective reversal medication for preventing postoperative residual neuromuscular blockade. Cochrane Database Syst Rev 7(4): CD007362.
24. Piskin Ö, Altinsoy B, Çimencan M, Aydin B G, Okyay D, et al. (2017) The effect of bariatric anesthesia on postoperative pulmonary functions. J Pak Med Assoc 67(4): 561-567.

Your next submission with Juniper Publishers will reach you the below assets

- Quality Editorial service

- Swift Peer Review

- Reprints availability

- E-prints Service

- Manuscript Podcast for convenient understanding

- Global attainment for your research

- Manuscript accessibility in different formats ( Pdf, E-pub, Full Text, Audio)

- Unceasing customer service

Track the below URL for one-step submission https://juniperpublishers.com/online-submission.php 